\title{
Gastrointestinal fistula endoscopic closure techniques
}

\author{
Abhishek Bhurwal ${ }^{a}$, Hemant Mutneja ${ }^{b}$, Augustine Tawadross ${ }^{a}$, Lauren Pioppo a, Bhaumik Brahmbhattc \\ Rutgers Robert Wood Johnson School of Medicine, New Brunswick, NJ; John H Stroger Cook County Hospital, \\ Chicago, Illinois; Mayo Clinic, Jacksonville, Florida, USA
}

\begin{abstract}
With the improvement in flexible endoscopic technology and the availability of new endoscopic devices, current endoscopic therapies spare many patients who would otherwise undergo surgical repair of gastrointestinal fistulas. These endoscopic techniques include gastrointestinal stents, endoscopic suturing, cardiac septal occluders, endo-sponge, vacuum therapy and others. This review elaborates on the indications, evidence, procedural details, efficacy, and complications of various endoscopic techniques for the management of gastrointestinal fistulas.
\end{abstract}

Keywords Gastrointestinal fistula, leak, endoscopy, suturing, stent, technique

Ann Gastroenterol 2020; 33 (6): 1-9

\section{Introduction}

A gastrointestinal fistula is an abnormal communication between the gastrointestinal epithelium and another organ or body surface. It was first reported in the early 1800 s, when Alexis St. Martin was shot in the abdomen by a musket and developed a gastro-cutaneous fistula [1]. St. Martin had to live with his condition for the rest of his life as it was not feasible to treat the fistula at that time [1]. Historically, a surgeon would often diagnose the condition, as most of the fistulas resulted from surgical procedures. The fistulas were also managed surgically for several decades, but the procedures were associated with high morbidity and mortality [2]. Over time, endoscopic therapy and interventional radiology started to expand their role in these cases. Endoscopic therapy with fibrin tissue adhesives for postoperative entero-cutaneous fistulas was first reported nearly 25 years ago [3]. Over the last 2 decades, improved clipping devices and the development of removal self-expandable metal stents (SEMS) led to a significant improvement in endoscopic techniques. With the improvement in flexible endoscopic technology and the availability of new endoscopic devices, a paradigm shift occurred in the management of gastrointestinal

Department of a Gastroenterology, Rutgers Robert Wood Johnson School of Medicine, New Brunswick, NJ (Abhishek Bhurwal, Augustine Tawadross, Lauren Pioppo); 'Department of Gastroenterology, John H Stroger Cook County Hospital, Chicago, Illinois (Hemant Mutneja); 'Department of Gastroenterology, Mayo Clinic, Jacksonville, Florida (Bhaumik Brahmbhatt), USA

Conflict of Interest: None

Correspondence to: Bhaumik Brahmbhatt, MBBS, Department of Gastroenterology, Mayo Clinic, 4500, San Pablo Road South, Jacksonville, Florida, USA, e-mail: brahmbhatt.bhaumik@mayo.edu

Received 4 May 2020; accepted 1 July 2020; published online 2 October 2020

DOI: https://doi.org/10.20524/aog.2020.0543 fistulas. Currently, endoscopic therapies spare many patients who would otherwise undergo surgical repair of fistulas. This review elaborates on the indications, evidence, procedural details and complications of various endoscopic techniques for the management of gastrointestinal fistulas.

The disruption of a surgical anastomosis is classified as a leak and leads to fluid collection [4]. However, a fistula is an abnormal connection between 2 epithelialized surfaces. Gastrointestinal fistulas are broadly classified into internal and external fistulas [4]. An internal fistula is an abnormal connection between gastrointestinal epithelium and an internal area (the peritoneal space, retroperitoneal space, thorax or another organ) [5]. External fistulas involve communication between the gastrointestinal organ and skin [5]. Fistulas can also be classified on the basis of etiology, anatomy (origin and ending site) or output (low output, $<500 \mathrm{~mL} /$ day; high output, $>500 \mathrm{~mL}$ /day) [6]. It is important to understand the etiology, anatomy and location of the fistula, as these factors play a major role in endoscopic closure. A high-volume fistula may be easily identifiable on the basis of imaging, but the endoscopic therapy does not depend on the output of the fistula alone. Fistulas can also be divided into acute and chronic: in acute fistula the inflammation is persistent, whereas in chronic fistula, inflammation has subsided. Historically, chronic fistulas are difficult to treat [2]. However, new endoscopic techniques demonstrate promising results even in chronic fistulas [7-10]. The majority of fistulas are a complication of surgical procedures, with varying rates of fistula formation $[5,11,12]$. The various etiologies are shown in Table 1.

\section{General considerations for treating fistulas}

The aim of the endoscopic therapy is to provide a barrier to the fistula site and restore luminal patency by application 
Table 1 Etiologies of gastrointestinal fistulas

\begin{tabular}{l} 
Postoperative \\
Crohn's disease \\
\hline Malignancy \\
Radiation \\
Foreign body \\
Chronic infections (tuberculosis, actinomycosis) \\
\hline Corrosive injury \\
Diverticular disease \\
\hline
\end{tabular}

Table 2 Endoscopic modalities for gastrointestinal fistula closure Stent Placement: FCSEMS, PCSEMS, SEPS

Clipping: TTSCs and OTSCs

Endoscopic suturing

Tissue sealants: fibrin glue and cyanoacrylate

Endoscopic vacuum therapy: endo-sponge

Cardiac septal occluders

FCSEMS, fully covered self-expandable metal stent; PCSEMS, partially covered self-expandable metal stent; SEPS, self-expandable plastic stent; TTSC, through-the-scope clip; OTSC, over-the-scope clip

of endoscopic techniques. Table 2 lists the various techniques used for the management of gastrointestinal leaks and fistulas. Despite the numerous techniques available, there are certain principles applicable to all techniques. Prior to endoscopic stent placement, a radiographic contrast study should be performed to assess the anatomy and location of the fistula site.

\section{Requirement of endoscopy units}

The endoscopist should have fluoroscopy equipment in the room. Nursing assistants adept at dealing with complex therapeutic procedures such as endoscopic retrograde cholangiopancreatography with metal stent placement should, ideally, be present at the time of the procedure.

\section{Diagnostic endoscopic workup}

Once informed consent has been obtained, a diagnostic endoscopy is first carried out. Once the fistulous opening is identified endoscopically, water-soluble radiopaque contrast is injected to confirm the defect and to evaluate the length and diameter of the fistula tract. This would also enable the endoscopist to delineate any other sites of leakage. The endoscopist should then clean the site under direct endoscopist visualization. It is imperative to examine the surrounding tissue for the presence or absence of inflammation or necrosis. This part is critical, as the surrounding tissue may determine the appropriate technique for the closure. Then, the fistula tract should be cautiously explored by passing the endoscope under direct visualization, provided that the luminal defect is wide enough. The leak cavity should be debrided under direct vision using aspiration, saline irrigation, and baskets or snares. The use of a fistula brush has been described in perianal fistulas to clean the fistula and remove the epithelium $[13,14]$. The brush consists of a semi-flexible wire with a brush section in the middle. However, minimal insufflation of $\mathrm{CO}_{2}$ should be used to avoid rupture, especially in newly formed thin walled cavities.

The use of hydrogen peroxide has been described to localize anal fistula $[15,16]$. Methylene blue can also be used during endoscopy to aid in the localization of fistula, especially gastro-cutaneous fistulas [17]. If an external drain is place, it can be submerged under water. $\mathrm{CO}_{2}$ insufflated through the endoscope will produce bubbles. Thereafter, methylene blue and water-soluble radiopaque contrast can be injected into the drain for localization of the leakage site. This enables the endoscopist to evaluate the leakage site accurately.

\section{Available therapies and post-procedure follow up}

Subsequently, the endoscopist should decide which next step will provide the maximum benefit in each individual scenario. Tables 3 and 4 provide details of the endoscopic modalities along with their advantages and limitations. Once the fistula site is closed, the adequacy of the closure should be evaluated during the procedure, immediately after the closure and during follow up. This is achieved by water-soluble contrast radiography or computed tomography, or by clinically measuring the output from the fistula site (if feasible).

\section{Individual endoscopic techniques}

\section{Stents}

Stents are cylindrical devices used to maintain or restore luminal patency in the gastrointestinal tract [18]. The placement of a luminal stent provides a transient barrier to the region, conceals the area of leakage and redirects gastrointestinal secretions away from the fistula tract. Luminal stents have been reported to be beneficial in the management of leakages or perforations involving the esophagus [19-21], stomach [12,22,23], and colon [24,25]. Luminal stents have been shown to result in earlier enteral feeding, a shorter hospital stay and lower in-hospital mortality as compared to conservative treatment [26].

Once the leakage site is confirmed endoscopically and the decision is made to place a stent, the endoscopist should select the stent. Stent selection is based on a number of features: (1) the type of stent to be deployed, plastic or metal; (2) fully covered, partially covered or uncovered; and (3) location of the fistula in the gastrointestinal tract. Currently available stents are made of either metal or plastic. The most common used 
Table 3 A summary of success rates for gastrointestinal fistulas

\begin{tabular}{lllc}
\hline Location of fistula & Etiology & Endoscopic modality & Success rate \\
\hline $\begin{array}{l}\text { Esophagus } \\
\text { (Tracheo-esophageal, broncho- } \\
\text { esophageal, esophagopleural) }\end{array}$ & $\begin{array}{l}\text { Malignant (esophageal cancer, lung } \\
\text { cancer, lymphoma) }\end{array}$ & FSEMS, PSEMS & $>90 \%$ \\
$\begin{array}{l}\text { Gastric } \\
\text { (Gastrocutaneous, gastro-gastric, } \\
\text { gastroduodenal, gastrocolonic) }\end{array}$ & $\begin{array}{l}\text { Post PEG tube removal, Post Bariatric } \\
\text { surgery, malignancy }\end{array}$ & $\begin{array}{l}\text { FSEMS, SEPS } \\
\text { Cardiac septal occluders }\end{array}$ & $76-83 \%$ \\
Colonic & & Endo-suturing & -- \\
$\begin{array}{l}\text { (Colovesical, colovaginal, } \\
\text { colocutaneous) }\end{array}$ & Post-surgical, malignancy, Crohn's & occluders & $75-89 \%$ \\
\hline
\end{tabular}

FCSEMS, fully covered self-expandable metal stent; PCSEMS, partially covered self-expandable metal stent; SEPS, self-expanding plastic stent; PEG, percutaneous endoscopic gastrostomy; TTSC, through-the-scope clip; OTSC, over-the-scope clip

metal alloy is nitinol, a mixture of nickel and titanium. Plastic stents are made of a polyester skeleton covered by a silicone membrane. More importantly, it is imperative to consider the covering of the stent before deployment. Uncovered stents become embedded within the wall, which prevents migration and makes stent extraction difficult, if not impossible. Addition of a silicone or polyurethane coat to the stent mesh, as in fully covered SEMS (FCSEMS), prevents tissue ingrowth and these stents are easily extractable. Partially covered SEMS (PCSEMS) have a small segment at the end that is not covered. Selfexpandable plastic stents are also fully covered stents but have a higher stent migration rate. The major factors that support stent placement are the high rates of excellent technical and clinical success [27]. Gubler et al reported successful closure of esophageal fistulas using SEMS with a success rate of 79\% [28]. Overall, SEMS have a clinical success rate of $76-83 \%$ in patients with benign upper gastrointestinal causes [19-21,24,28-31]. Table 1 summarizes the different stents available for endoscopic fistula closure.

Once the fistula is identified, a guidewire is advanced well beyond the leakage site. There are then 2 methods of deploying the stent: (1) non-through-the-scope placement, or side-byside technique placement; and (2) through-the-scope (TTS) placement. The fluoroscopically placed SEMS technique involves leaving the guidewire in place and withdrawing the endoscope. The stent is then loaded onto the guidewire and advanced to the lesion under fluoroscopy. The endoscope is then advanced along the stent delivery system to allow visualization. However, the stent delivery system often tends to loop (especially if deploying the stent in the colon) as it has poor mechanical support. Therefore, to assist the passage of the stent, the endoscopist can: (a) utilize a snare over the delivery system, which then enables advancing the endoscope and snare over the delivery system; (b) use a rat-tooth forceps to advance the stent delivery system forward; or (c) use extension of the delivery. In contrast, the TTS technique involves an endoscope with a working therapeutic channel. After the guidewire is in position, the stent in advanced over the guidewire under direct endoscopic guidance. The stent is then deployed from the distal end. Once the stent is deployed, its ends should be carefully inspected using fluoroscopy. If there is a suspicion of either end not expanding completely, then contrast should be injected to assess the position. The stent could be clipped or sutured to secure its placement [32]. Honneger et al described the use of over-the-scope clips in fixation of stents [33]. If needed, a plastic stent can be placed inside the metal stent. Once the stent has been successfully deployed, it is left in place for approximately 6 weeks to allow for healing of mucosa and fistula closure [27,34]. If the interval is shorter, then the fistula tract will not close completely. Stent removal is performed by an endoscopic grasper pulling at one edge of the stent. The stents are then removed between 4 and 8 weeks, as removal could be difficult beyond 8 weeks. If the stent is embedded, then argon plasma coagulation may be used to facilitate stent removal. Another technique that has been described for the removal of an imbedded stent is the stent-in-stent technique. This involves the placement of a fully covered metal stent inside the embedded, partially covered metal stent. The embedded mucosal tissue between the 2 stents undergoes necrosis. Approximately 14 days later, another endoscopy is performed to remove both stents [35-37].

The most common complications with gastrointestinal stent placement are intraluminal bleeding and/or perforation (reported in up to $3 \%$ of cases) [27]. Another common complication is stent migration, which occurs in $26-30 \%$ of FCSEMS and approximately $10 \%$ of PCSEMS $[21,27]$. However, endoscopic interventions such as clips have decreased the rate of migration in PCSEMS $[32,33,38]$. These patients would need endoscopic intervention and/or surgical therapy to retrieve the stent. Therefore, FCSEMS are often clipped or sutured to maintain their placement. In contrast to covered stents, uncovered stents are overgrown by epithelium in up to $12 \%$ of cases $[27,34]$. Sometimes, stents can get obstructed by food. Endoscopic reinterventions are often needed, in $26 \%$ of patients with FCSEMS and 13\% with PCSEMS [34]. If leaks persist, re-stenting could be considered.

Endoscopic stenting has been the preferred treatment for several years. However, with the advent of newer therapies, it can be expected that specific indications for stent placement in gastrointestinal fistulas will be determined.

\section{Endoscopic clips}

Endoscopic clipping has been tried for several years for closure of gastrointestinal fistulas. Multiple TTS clips (TTSCs) are often 
used to close small mucosal defects $[39,40]$. The advantages include ease of use and the ability to reopen the clip and rotate the clip if needed. However, the small diameter and low compression force do not allow full thickness closure of gastrointestinal leaks [41]. TTSCs may not be able to approximate the surrounding tissue if there is inflammation or necrotic tissue. TTSCs may also spontaneously dislodge, which limits their duration of use.

The over-the-scope clip (OTSC) (Fig. 1) changed the basic principles of clip placement and overcomes the limitations of TTSCs. It is made of nitinol and has a bear-claw shape with a plastic cap. There are 3 different cap diameters $(11,12$ and $14 \mathrm{~mm}$ ) for Ovesco clips, with different cap heights $(3 \mathrm{~mm}$ and $6 \mathrm{~mm}$ ). The cap height determines the amount of tissue that can be pulled into the cap. A cap height of $6 \mathrm{~mm}$ is used for the majority of closures. The teeth of the clips may also have different shapes: atraumatic, blunt, sharp and special geometry teeth. The padlock-G clip is another available system, consisting of a preloaded hexagonal nitinol clip with a plastic cap [42].

It is also good practice to check the accessibility of the site with a standard device cap mounted on the endoscope. This can avoid unnecessary time and costs for mounted OTSC where the clips cannot be placed. The assembly and deployment are similar to that of a variceal band ligation device. Once the OTSC is loaded onto the endoscope, tissue is pulled into the cap via suction or instruments introduced via the working channel. There are 2 instruments that can be used to grasp the tissue: the anchor and the twin grasper. The anchor has 3 hooks to pull the tissue into the cap. The twin grasper has 2 independently opening branches on each side to grasp the defects separately. It is imperative to have both edges within the cap properly deployed. The clip is then deployed by turning a hand-wheel attached to the endoscope. The OTSC may incise the mucosa if the surrounding tissue is weak or friable or necrotic. Therefore, a thorough endoscopic examination is recommended before the clip is deployed. The OTSC has been reported to close defects up to $2 \mathrm{~cm}$ in diameter in the stomach and $3 \mathrm{~cm}$ in the colon. Larger defects may require more than 1 OTSC or additional TTSCs to achieve closure [43]. It is also imperative to check if there is a cavity behind the fistula tract, as the OTSC would prohibit any debridement.

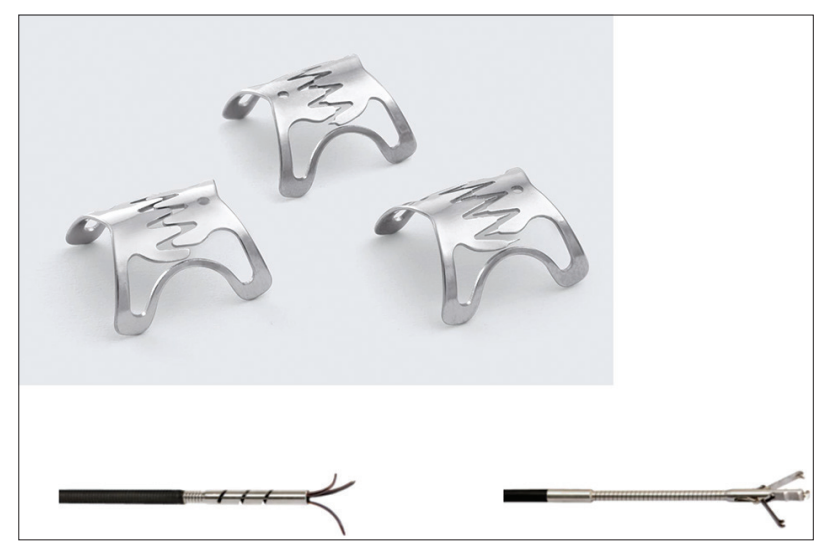

Figure 1 Over-the-scope clips: top - multiple types of clip; bottom left anchor; bottom right - grasper
Multiple retrospective studies have shown promising results for OTSCs for closure of gastrointestinal fistulas, with an initial success rate of $75-89 \%$ [44-47]. Despite the high technical and clinical success, there are certain limitations. The long-term clinical efficacy of OTSCs for fistulas closure is still uncertain. Honneger et al reported a long-term fistula closure rate of approximately $29.8 \%$ [33]. Even though few complications have been reported, some have been severe. The introduction of an OTSC could injure the upper esophagus or the anal canal. A persistent leak would be the result of incorrect positioning of the OTSC. In these cases, a second OTSC can be used. However, the placement of a second OTSC can be challenging. The removal of an incorrectly placed OTSC is also demanding. This entails the use of a bipolar forceps introduced via the working channel. The clip is then grasped at the thinnest point. A short electric impulse then breaks the clips at the thinnest portion. The clip is then extracted using a protective plastic cap.

\section{Suturing}

Novel suturing techniques allow for full thickness closure of gastrointestinal luminal defects. Even though closure of fistulas has been demonstrated, it is a technically complex procedure. Therefore, only endoscopists trained in endoscopic suturing should perform these procedures, which limits their adoption. Suturing requires relatively healthy mucosa around the fistula defect to hold the sutures together [39]. Endoscopic suturing allows for closure of large defects compared to clips (more than $2 \mathrm{~cm}$ in size).

Currently, endoscopic suturing is performed using an OverStitch device (Apollo, Endosurgery, Austin, TX, USA) (Fig. 2), compatible with a double channel therapeutic endoscope. The device has a handle attached to the hub of the endoscope. The handle controls the metallic needle arm attached to the tip of the endoscope. The device places continuous or intermittent sutures without removal of the scope. The tissue is approximated by tissue-retracting device or forceps. Full thickness sutures are placed using a tissue helix catheter [48].

Suturing is especially effective in the management of fistulas developing after bariatric surgery. 95\% of the patients had complete closure in a large series that compared endoscopic suturing with endoscopic clipping for the management of gastro-gastric fistula after Roux-en-Y gastric bypass [49]. However, reopening was noticed in 65\% [49]. There are case series describing successful closure using multiple techniques, including suturing [50]. However, the data should be viewed with caution given the limited information. In addition, suturing is a complicated process in different locations of the gastrointestinal tract. Therefore, suturing techniques need further modification to become a successful therapy for fistula closure.

\section{Tissue sealants}

Eleftheriadis et al first reported the use of sealant for gastrointestinal fistula closure [3]. Since then, multiple reports 

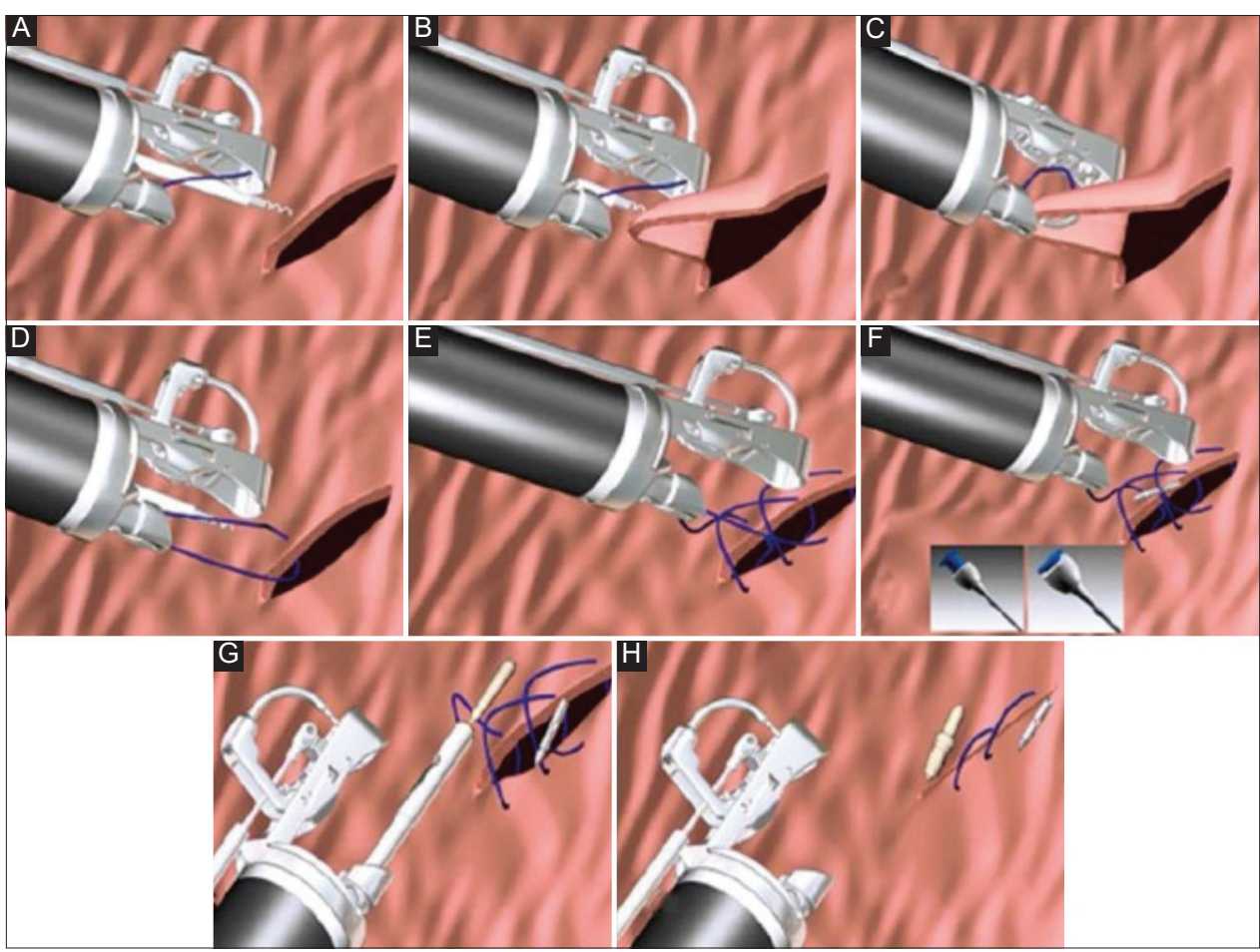

Figure 2 Steps involved in placing endoscopic sutures. (A) Grasp the tissue using the tissue helix; (B) retract the tissue into the needle path; (C) drive the needle through; (D) open the arm and release the tissue; (E) repeat the stitch as desired; (F) Press the button to release the needle; (G) tighten and cinch; $(\mathrm{H})$ repeat as desired

have been published describing the success of sealants. Fibrin glue and cyanoacrylate are the tissue adhesives used to seal gastrointestinal defects. Cyanoacrylate has stronger adhesion properties compared to fibrin glue, due to its ability to polymerize after contact with anions. Cyanoacrylate is not affected by gastric or pancreatic enzymes, allowing the successful closure of fistulas [51]. On the other hand, the use of fibrin is challenging, as it performs better in dry areas [52]. Fibrin-based sealant blocks the passage of gastrointestinal contents through the fistula and promotes tissue repair.

The most common sites of sealant application include endoscopically accessible areas, such as post-anastomotic leakages in the upper gastrointestinal tract and post-bariatric surgery leaks or fistulas. The application of the sealant involves de-epithelialization of tissue around the fistula, which leads to an inflammatory response when the fistula is sealed. This can be performed in 2 ways: (1) a standard biliary cytology brush can be used to abrade the edges; (2) Argon plasma coagulation at a low power setting can also be utilized. Subsequently, a double-lumen catheter is inserted into the endoscope to prevent components of the sealant reacting and bonding within the scope. The amount of adhesive needed depends on the size of the fistula. Often, multiple applications are required.

Multiple studies have evaluated the efficacy of sealants in the management of gastrointestinal fistulas. Lippert et al reported successful closure in $36.5 \%$ with fibrin alone, compared to $55.7 \%$ with additional endoscopic therapy [53]. Avalos-Gonzalez et al reported earlier fistula closure and decreased morbidity in the fibrin-treated group compared to controls [54]. A metaanalysis reviewing 14 studies that evaluated the efficacy of cyanoacrylate reported a success rate of $81 \%$ [55]. Despite the high success rate, high-output gastrointestinal fistulas are less likely to be successfully closed by sealant alone.

In addition to the above, vicryl mesh and soft tissue grafts (such as Surgisis) are also used for the closure of fistulas [56]. In a case series, complete closure of gastro-cutaneous fistulas was achieved in $80 \%$ of the cases using vicryl mesh [57]. For larger diameter fistulas, combination therapy could be utilized. Böhm et al have described promising results with a combination of vicryl and fibrin glue [58].

The anal fistula plug, or Surgisis (Fig. 3), is made of a fibrogenic matrix that prevents foreign body reactions. This was initially developed for the management of anorectal fistulas [59]. The fistula plug is deployed under fluoroscopic guidance. A guidewire is inserted into the external fistula opening and then advanced under fluoroscopic guidance until visualized endoscopically. The guidewire can then be attached to the fistula plug. The snare is then attached to the guidewire and passed through the fistula to the outside, carrying the narrower end of the plug into the tract. Multiple plugs might be needed to close the fistula. Toussaint et al reported healing of 4 of the enterocutaneous fistulas [56]. A larger study revealed a clinical success rate of $75 \%$ in gastro-cutaneous fistulas [57].

The role of tissue adhesives in the management of gastrointestinal tract fistulas is still evolving. Although these agents may not be great candidates as individual therapy, they 
Table 4 Comparison of endoscopic modalities in terms of advantages and disadvantages

\begin{tabular}{|c|c|c|}
\hline Endoscopic modality & Advantages & Limiting factor \\
\hline $\begin{array}{l}\text { Stent placement } \\
\text { (FSEMS, PSEMS, SEPS) }\end{array}$ & High technical and clinical success rates & $\begin{array}{l}\text { Stent migration (can be mitigated by reinforcement with endoclips } \\
\text { or sutures) } \\
\text { Embedding of stent hindering removal (can be eased by APC or } \\
\text { stent-in-stent technique) }\end{array}$ \\
\hline $\begin{array}{l}\text { Clipping: } \\
\text { TTSC or OTSC }\end{array}$ & Easy to use & $\begin{array}{l}\text { Restricted to up to } 2-3 \mathrm{~cm} \text { sized defects } \\
\text { Delayed recurrence is high }\end{array}$ \\
\hline Endoscopic suturing & $\begin{array}{l}\text { Can be used for large sized }(>3 \mathrm{~cm}) \\
\text { defects }\end{array}$ & Requires high technical expertise \\
\hline $\begin{array}{l}\text { Tissue sealants: } \\
\text { fibrin glue and cyanoacrylate }\end{array}$ & $\begin{array}{l}\text { High success rate for low-output and } \\
\text { small sized fistulas }\end{array}$ & $\begin{array}{l}\text { Monotherapy may not be effective and usually requires } \\
\text { combination with other techniques }\end{array}$ \\
\hline Endoscopic vacuum therapy & $\begin{array}{l}\text { Can be used in critically ill and unstable } \\
\text { patients in need of infectious source } \\
\text { control }\end{array}$ & Bleeding due to ingrowth of granulation tissue into endo-sponge \\
\hline
\end{tabular}

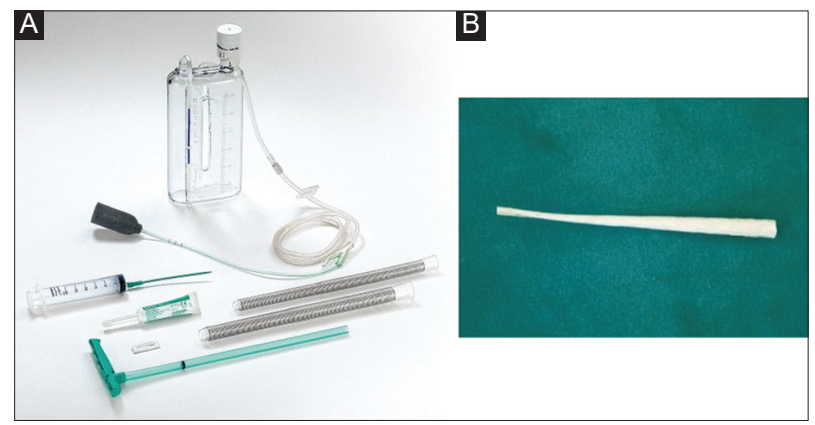

Figure 3 (A) Endo-sponge with the device; (B) Anal fistula plug

could be used in combination with other therapies. Further prospective studies are needed to determine the efficacy and advantages of combining adhesive therapy with other endoscopic techniques.

\section{Endoscopic vacuum therapy or endo-sponge}

Endoscopic vacuum-assisted closure (EVAC) or endosponge (Fig. 4) is an emerging, minimally invasive technique. The EVAC delivers negative pressure to the site to collapse the cavity and create a seal [60]. The device consists of a sponge and tube attached to external vacuum suction. This leads to a gentle, continuous suction over the tissue that removes secretions and induces the formation of granulation tissue. The endo-sponge can be placed either within the cavity or within the lumen and completely covering the leak site.

Once the site is identified, the cavity is irrigated and debrided endoscopically. After the site has been identified, the endo-sponge is selected. Depending on the size of the perforation, the endoscope should evaluate the site of the leak (if the size is $<1 \mathrm{~cm}$ ) or evaluate the cavity (if the size is $>1 \mathrm{~cm}$ ). For upper gastrointestinal leaks, a nasogastric tube is placed through the nose and pulled out through the mouth to attach the endo-sponge. The endo-sponge is then secured to the tube

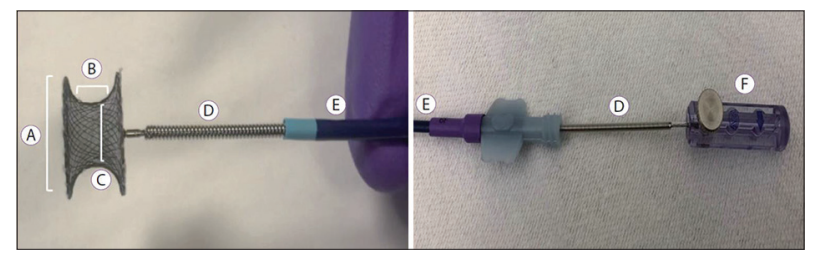

Figure 4 Cardiac septal occluder with assembly. (A) Disc diameter; (B) waist length; (C) Device size; (D) Delivery cable; (E) Sheath; (F) Plastic vise

using a strong permanent suture. An endoscopic grasper is then utilized to carry the endo-sponge via another suture at the other end and place the endo-sponge in the desired location. Thus, once the ideal location has been confirmed, negative pressure is applied. The endo-sponge needs to be changed frequently, usually between 3 and 5 days. Removal of the endosponge should be carried out under endoscopic vision once the leak site is completely sealed.

Weidenhagen et al described the use of EVAC in 2003 for the management of anastomotic leaks after rectal surgery [61]. A later systematic review of 17 colorectal studies showed an average healing rate of $85 \%$ after a median follow up of 47 days [62]. Over the last few years, EVAC therapy has been used in anastomotic leaks of the esophagus. Successful closure was also achieved in 7 of 8 patients with intrathoracic anastomotic leaks [63]. A review of 29 studies showed a healing rate of $67-100 \%$ with EVAC for esophageal leaks [64], the most common indication for EVAC therapy. EVAC therapy is also utilized to treat gastric leaks, especially after bariatric surgery [65].

There have been few reported adverse events for EVAC. The usual complaint is patient discomfort from nasogastric tube placement $[65,66]$. Other adverse events include sponge dislocation, minor bleeding due to sponge exchange, and anastomotic strictures $[65,66]$. If significant bleeding occurs during the treatment, EVAC should be discontinued and abdominal imaging should be pursued. 


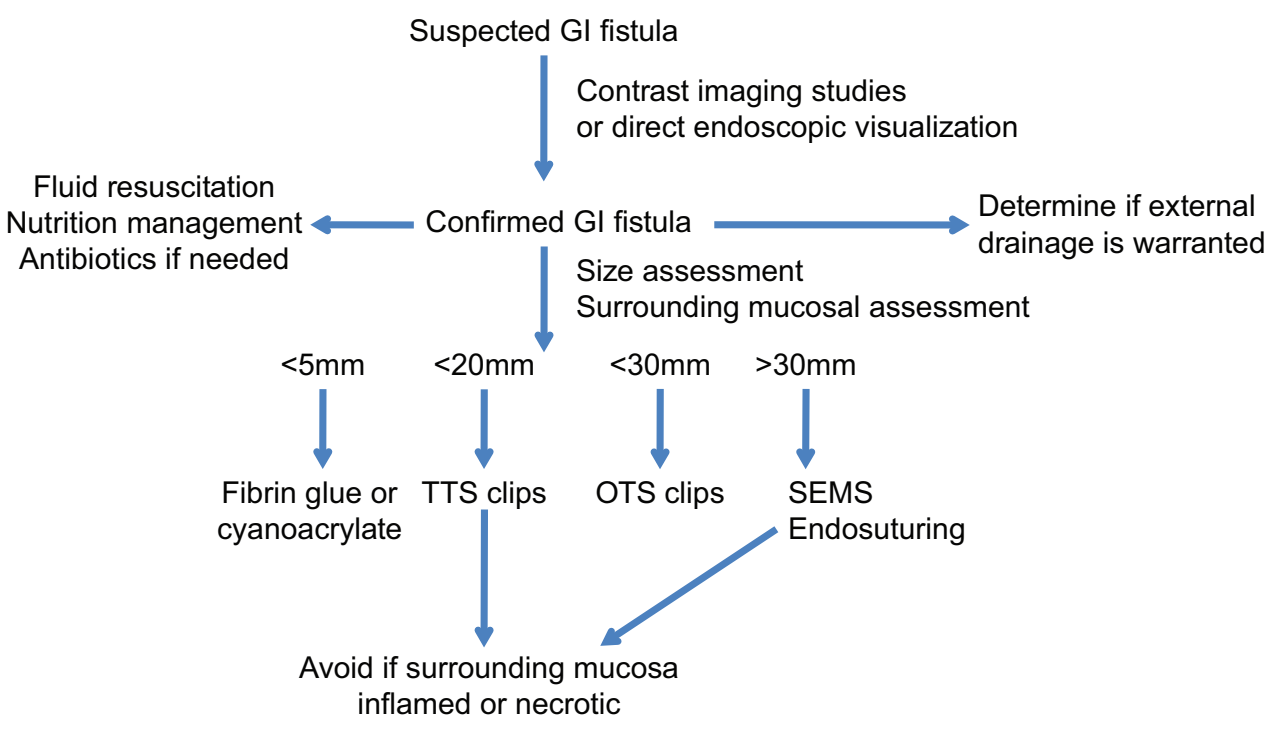

Figure 5 Flow chart for management of gastrointestinal fistulae

\section{Cardiac septal occluders (CSO)}

Cardiac septal occluders (Fig. 5) are self-expanding double-disc closure devices that promote tissue occlusion. There are 2 types of CSO available for the management of gastrointestinal fistulas: atrial septal defect closure device and ventricle septal defect closure device. CSOs are made of nitinol, with a similar structure to the enteral stent. They are deployed via a delivery system using a guidewire under direct endoscopic visualization. Another technique involves backloading the CSO into a 7-10 Fr endoscopic biliary catheter. A biopsy forceps is then used to deploy the stent.

In a recent systematic review, technical success was achieved in all cases $(n=22) ; 77.27 \%$ had successful closure with a mean follow up of 8 months [67]. However, the majority of cases have been case reports and it is therefore not possible to ascertain publication bias, complications or long-term efficacy. Prospective studies are imperative to clarify their role in the management of gastrointestinal fistulas.

\section{Concluding remarks}

Gastrointestinal fistulas are challenging to manage, as exposure to gastrointestinal secretions results in inflammation. Altered anatomy, malignancy or associated radiation injury further complicates management. The various endoscopic techniques have been described in the previous sections.

Although every technique has been described separately, often a combination of techniques is used to manage gastrointestinal fistulas. Regardless of the specific techniques, certain principles are common to management. Multidisciplinary care can provide benefit in the long term. The teams involved are interventional endoscopy, interventional radiology, surgery and nutrition. Each clinical scenario is unique and endoscopic therapy needs to be individualized for every patient. The second step involves defining and delineating the fistula. After identification of the fistula, drainage of fluid collection or cavity should be considered. Subsequently, a thorough and careful evaluation of the tissue surrounding the fistula is performed. This is critical, as it will determine which technique would be suitable. The presence of friable necrotic tissue makes the application of TTSCs or suturing challenging. Selection of the technique often depends on the location, size of the defect, surrounding tissue and experience of the endoscopist with different techniques. Gastric fistulas are infrequent and are noticed following percutaneous gastrostomy tube removal or post bariatric surgery $[5,68]$. Immediate closure is highly successful using OTSC in the setting of benign esophageal, gastric and colonic fistulas [47]. The endoscopist should place the OTSC carefully, as OTSC removal is demanding. Additionally, the long-term success of OTSC for fistula closure has been disappointing $[46,47,69]$. Other less common methods include endoscopic suturing and sealant application. Sethi et al reported initial clinical success in $62 \%$ of patients with benign disease using an endoscopic suturing technique [70]. However, long-term results are still lacking for endoscopic suturing. Esophageal fistulas may also be best treated with a combination therapy. Small fistula defects (less than $1 \mathrm{~cm}$ ) or proximal esophageal fistulas could be managed with TTSCs. However, larger defects (more than $2 \mathrm{~cm}$ ) would need OTSCs or placement of FCSEMS to divert enteral feeds. Similarly, stents or suturing or OTSCs could be utilized in colonic fistulas. The technique utilized should successfully interrupt the flow of the luminal contents. Fistula closure should ideally be confirmed at the time of the procedure, after closure and during follow up.

Despite the evolution of endoscopic techniques over the last decade, the management of gastrointestinal fistulas remains a challenge. Advanced endoscopic methods provide for a less invasive and more physiological approach to the treatment. 
However, long-term success rates and efficacy are not described at this time. Despite the high technical and clinical success, some endoscopic fistulas may not be amenable to endoscopic therapy. Therefore, a multidisciplinary approach is needed. For the gastrointestinal fistulas amenable to endoscopic therapy, endoscopic closures represent significant progress in the minimally invasive management of gastrointestinal leaks and fistulas.

\section{References}

1. Rutkow IM. Beaumont and St Martin: a blast from the past. Arch Surg 1998;133:1259.

2. Schecter WP, Hirshberg A, Chang DS, et al. Enteric fistulas: principles of management. J Am Coll Surg 2009;209:484-491.

3. Eleftheriadis E, Tzartinoglou E, Kotzampassi K, Aletras H. Early endoscopic fibrin sealing of high-output postoperative enterocutaneous fistulas. Acta Chir Scand 1990;156:625-628.

4. Kumar N, Thompson CC. Endoscopic therapy for postoperative leaks and fistulae. Gastrointest Endosc Clin N Am 2013;23:123-136.

5. Falconi M, Pederzoli P. The relevance of gastrointestinal fistulae in clinical practice: a review. Gut 2001;49 Suppl 4:iv2-iv10.

6. González-Pinto I, González EM. Optimising the treatment of upper gastrointestinal fistulae. Gut 2001;49 Suppl 4:iv22-iv31.

7. Singhal S, Changela K, Culliford A, Duddempudi S, Krishnaiah M, Anand S. Endoscopic closure of persistent gastrocutaneous fistulae, after percutaneous endoscopic gastrostomy (PEG) tube placement, using the over-the-scope-clip system. Therap Adv Gastroenterol 2015;8:182-188.

8. Spaun GO, Martinec DV, Kennedy TJ, Swanström LL. Endoscopic closure of gastrogastric fistulas by using a tissue apposition system (with videos). Gastrointest Endosc 2010;71:606-611.

9. Eskaros S, Ghevariya V, Krishnaiah M, Asarian A, Anand S. Percutaneous endoscopic suturing: an effective treatment for gastrocutaneous fistula. Gastrointest Endosc 2009;70:768-771.

10. Duddempudi S, Ghevariya V, Singh M, Krishnaiah M, Anand S. Treatment of persistently leaking post PEG tube gastrocutaneous fistula in elderly patients with combined electrochemical cautery and endoscopic clip placement. South Med J 2009;102:585-588.

11. Elder KA, Wolfe BM. Bariatric surgery: a review of procedures and outcomes. Gastroenterology 2007;132:2253-2271.

12. Eisendrath P, Cremer M, Himpens J, Cadière GB, Le Moine O, Devière J. Endotherapy including temporary stenting of fistulas of the upper gastrointestinal tract after laparoscopic bariatric surgery. Endoscopy 2007;39:625-630.

13. Zmora O, Scott D, Khaikin M, Venturero M, Koller M. Pipe cleaner brush for "curettage" of perianal fistulas. Tech Coloproctol 2004;8:116.

14. Zmora O, Neufeld D, Ziv Y, et al. Prospective, multicenter evaluation of highly concentrated fibrin glue in the treatment of complex cryptogenic perianal fistulas. Dis Colon Rectum 2005;48:2167-2172.

15. Gunawardhana PA, Deen KI. Comparison of hydrogen peroxide instillation with Goodsall's rule for fistula-in-ano. ANZ J Surg 2001;71:472-474.

16. Kruskal JB, Kane RA, Morrin MM. Peroxide-enhanced anal endosonography: technique, image interpretation, and clinical applications. Radiographics 2001;21 Spec No:S173-S189.

17. Kumar N, Thompson CC. Endoscopic management of complications after gastrointestinal weight loss surgery. Clin Gastroenterol Hepatol 2013;11:343-353.

18. Varadarajulu S, Banerjee S, Barth B, et al; ASGE Technology
Committee. Enteral stents. Gastrointest Endosc 2011;74:455-464.

19. Bakken JC, Wong Kee Song LM, de Groen PC, Baron TH. Use of a fully covered self-expandable metal stent for the treatment of benign esophageal diseases. Gastrointest Endosc 2010;72:712-720.

20. Eloubeidi MA, Talreja JP, Lopes TL, Al-Awabdy BS, Shami VM, Kahaleh M. Success and complications associated with placement of fully covered removable self-expandable metal stents for benign esophageal diseases (with videos). Gastrointest Endosc 2011;73:673-681.

21. Buscaglia JM, Ho S, Sethi A, et al. Fully covered self-expandable metal stents for benign esophageal disease: a multicenter retrospective case series of 31 patients. Gastrointest Endosc 2011;74:207-211.

22. Salinas A, Baptista A, Santiago E, Antor M, Salinas H. Selfexpandable metal stents to treat gastric leaks. Surg Obes Relat Dis 2006;2:570-572.

23. Garofalo F, Noreau-Nguyen M, Denis R, Atlas H, Garneau P, Pescarus R. Evolution of endoscopic treatment of sleeve gastrectomy leaks: from partially covered to long, fully covered stents. Surg Obes Relat Dis 2017;13:925-932.

24. Lamazza A, Sterpetti AV, De Cesare A, Schillaci A, Antoniozzi A, Fiori E. Endoscopic placement of self-expanding stents in patients with symptomatic anastomotic leakage after colorectal resection for cancer: long-term results. Endoscopy 2015;47:270-272.

25. DiMaio CJ, Dorfman MP, Gardner GJ, et al. Covered esophageal self-expandable metal stents in the nonoperative management of postoperative colorectal anastomotic leaks. Gastrointest Endosc 2012;76:431-435.

26. Hünerbein M, Stroszczynski C, Moesta KT, Schlag PM. Treatment of thoracic anastomotic leaks after esophagectomy with selfexpanding plastic stents. Ann Surg 2004;240:801-807.

27. van Boeckel PG, Sijbring A, Vleggaar FP, Siersema PD. Systematic review: temporary stent placement for benign rupture or anastomotic leak of the oesophagus. Aliment Pharmacol Ther 2011;33:1292-1301.

28. Gubler C, Bauerfeind P. Self-expandable stents for benign esophageal leakages and perforations: long-term single-center experience. Scand J Gastroenterol 2014;49:23-29.

29. van Halsema EE, Rauws EA, Fockens P, van Hooft JE. Selfexpandable metal stents for malignant gastric outlet obstruction: A pooled analysis of prospective literature. World J Gastroenterol 2015;21:12468-12481.

30. Swinnen J, Eisendrath P, Rigaux J, et al. Self-expandable metal stents for the treatment of benign upper GI leaks and perforations. Gastrointest Endosc 2011;73:890-899.

31. Dai Y, Chopra SS, Kneif S, Hünerbein M. Management of esophageal anastomotic leaks, perforations, and fistulae with self-expanding plastic stents. J Thorac Cardiovasc Surg 2011;141:1213-1217.

32. Vanbiervliet G, Filippi J, Karimdjee BS, et al. The role of clips in preventing migration of fully covered metallic esophageal stents: a pilot comparative study. Surg Endosc 2012;26:53-59.

33. Honegger C, Valli PV, Wiegand N, Bauerfeind P, Gubler C. Establishment of Over-The-Scope-Clips $\left(\mathrm{OTSC}^{\circledR}\right)$ in daily endoscopic routine. United European Gastroenterol J 2017;5:247-254.

34. Puli SR, Spofford IS, Thompson CC. Use of self-expandable stents in the treatment of bariatric surgery leaks: a systematic review and meta-analysis. Gastrointest Endosc 2012;75:287-293.

35. Evrard S, Le Moine O, Lazaraki G, Dormann A, El Nakadi I, Devière J. Self-expanding plastic stents for benign esophageal lesions. Gastrointest Endosc 2004;60:894-900.

36. Langer FB, Schoppmann SF, Prager G, Riegler FM, Zacherl J. Solving the problem of difficult stent removal due to tissue ingrowth in partially uncovered esophageal self-expanding metal stents. Ann Thorac Surg 2010;89:1691-1692.

37. Hirdes MM, Vleggaar FP, Van der Linde K, Willems M, Totté ER, 
Siersema PD. Esophageal perforation due to removal of partially covered self-expanding metal stents placed for a benign perforation or leak. Endoscopy 2011;43:156-159.

38. Shim CS, Cho YD, Moon JH, et al. Fixation of a modified covered esophageal stent: its clinical usefulness for preventing stent migration. Endoscopy 2001;33:843-848.

39. Willingham FF, Buscaglia JM. Endoscopic management of gastrointestinal leaks and fistulae. Clin Gastroenterol Hepatol 2015;13:1714-1721.

40. Rodella L, Laterza E, De Manzoni G, et al. Endoscopic clipping of anastomotic leakages in esophagogastric surgery. Endoscopy 1998;30:453-456.

41. Rustagi T, McCarty TR, Aslanian HR. Endoscopic treatment of gastrointestinal perforations, leaks, and fistulae. J Clin Gastroenterol 2015;49:804-809.

42. Guarner-Argente C, Córdova H, Martínez-Pallí G, et al. Yes, we can: reliable colonic closure with the Padlock-G clip in a survival porcine study (with video). Gastrointest Endosc 2010;72:841-844.

43. Matthes K, Jung Y, Kato M, Gromski MA, Chuttani R. Efficacy of full-thickness GI perforation closure with a novel over-thescope clip application device: an animal study. Gastrointest Endosc 2011;74:1369-1375.

44. Mönkemüller K, Peter S, Toshniwal J, et al. Multipurpose use of the 'bear claw' (over-the-scope-clip system) to treat endoluminal gastrointestinal disorders. Dig Endosc 2014;26:350-357.

45. Voermans RP, Le Moine O, von Renteln D, et al; CLIPPER Study Group. Efficacy of endoscopic closure of acute perforations of the gastrointestinal tract. Clin Gastroenterol Hepatol 2012;10:603-608.

46. Law R, Wong Kee Song LM, Irani S, Baron TH. Immediate technical and delayed clinical outcome of fistula closure using an over-the-scope clip device. Surg Endosc 2015;29:1781-1786.

47. Manta R, Manno M, Bertani H, et al. Endoscopic treatment of gastrointestinal fistulas using an over-the-scope clip (OTSC) device: case series from a tertiary referral center. Endoscopy 2011;43:545-548.

48. Banerjee S, Barth BA, Bhat YM, et al; ASGE Technology Committee. Endoscopic closure devices. Gastrointest Endosc 2012;76:244-251.

49. Fernandez-Esparrach G, Lautz DB, Thompson CC. Endoscopic repair of gastrogastric fistula after Roux-en-Y gastric bypass: a lessinvasive approach. Surg Obes Relat Dis 2010;6:282-288.

50. Bonin EA, Wong Kee Song LM, Gostout ZS, Bingener J, Gostout CJ. Closure of a persistent esophagopleural fistula assisted by a novel endoscopic suturing system. Endoscopy 2012;44 Suppl 2 UCTN:E8-E9.

51. Kotzampassi K, Eleftheriadis E. Tissue sealants in endoscopic applications for anastomotic leakage during a 25-year period. Surgery 2015;157:79-86.

52. Rogalski P, Daniluk J, Baniukiewicz A, Wroblewski E, Dabrowski A. Endoscopic management of gastrointestinal perforations, leaks and fistulas. World J Gastroenterol 2015;21:10542-10552.

53. Lippert E, Klebl FH, Schweller F, et al. Fibrin glue in the endoscopic treatment of fistulae and anastomotic leakages of the gastrointestinal tract. Int J Colorectal Dis 2011;26:303-311.

54. Avalos-González J, Portilla-deBuen E, Leal-Cortés CA, et al. Reduction of the closure time of postoperative enterocutaneous fistulas with fibrin sealant. World J Gastroenterol 2010;16:2793-2800.

55. López J, Rodriguez K, Targarona EM, et al. Systematic review of cyanoacrylate embolization for refractory gastrointestinal fistulae: a promising therapy. Surg Innov 2015;22:88-96.

56. Toussaint E, Eisendrath P, Kwan V, Dugardeyn S, Devière J, Le Moine O. Endoscopic treatment of postoperative enterocutaneous fistulas after bariatric surgery with the use of a fistula plug: report of five cases. Endoscopy 2009;41:560-563.

57. Maluf-Filho F, Hondo F, Halwan B, de Lima MS, GiordanoNappi JH, Sakai P. Endoscopic treatment of Roux-en-Y gastric bypass-related gastrocutaneous fistulas using a novel biomaterial. Surg Endosc 2009;23:1541-1545.

58. Böhm G, Mossdorf A, Klink C, et al. Treatment algorithm for postoperative upper gastrointestinal fistulas and leaks using combined vicryl plug and fibrin glue. Endoscopy 2010;42:599-602.

59. Champagne BJ, O'Connor LM, Ferguson M, Orangio GR, Schertzer ME, Armstrong DN. Efficacy of anal fistula plug in closure of cryptoglandular fistulas: long-term follow-up. Dis Colon Rectum 2006;49:1817-1821.

60. Szymanski K, Ontiveros E, Burdick JS, Davis D, Leeds SG. Endolumenal vacuum therapy and fistulojejunostomy in the management of sleeve gastrectomy staple line leaks. Case Rep Surg 2018;2018:2494069.

61. Holle G, Germann G, Sauerbier M, Riedel K, von Gregory H, Pelzer M. [Vacuum-assisted closure therapy and wound coverage in soft tissue injury. Clinical use]. Unfallchirurg 2007;110:289-300.

62. Shalaby M, Emile S, Elfeki H, Sakr A, Wexner SD, Sileri P. Systematic review of endoluminal vacuum-assisted therapy as salvage treatment for rectal anastomotic leakage. BJS Open 2019;3:153-160.

63. Weidenhagen R, Gruetzner KU, Wiecken T, Spelsberg F, Jauch KW. Endoscopic vacuum-assisted closure of anastomotic leakage following anterior resection of the rectum: a new method. Surg Endosc 2008;22:1818-1825.

64. Virgilio E, Ceci D, Cavallini M. Surgical endoscopic vacuumassisted closure therapy (EVAC) in treating anastomotic leakages after major resective surgery of esophageal and gastric cancer. Anticancer Res 2018;38:5581-5587.

65. Leeds SG, Burdick JS. Management of gastric leaks after sleeve gastrectomy with endoluminal vacuum (E-Vac) therapy. Surg Obes Relat Dis 2016;12:1278-1285.

66. Laukoetter MG, Mennigen R, Neumann PA, et al. Successful closure of defects in the upper gastrointestinal tract by endoscopic vacuum therapy (EVT): a prospective cohort study. Surg Endosc 2017;31:2687-2696.

67. de Moura DTH, Ribeiro IB, Funari MP, Baptista A, Thompson CC, de Moura EGH. Novel use of a cardiac septal occluder to treat a chronic recalcitrant bariatric fistula after Roux-en-Y gastric bypass. Endoscopy 2019;51:E111-E112.

68. McElrath L, Pauli EM, Marks JM. Hernia formation and persistent fistula after percutaneous endoscopy gastrostomy: unusual complications of a common procedure. Am Surg 2012;78:E200-E201.

69. Gelbmann CM, Ratiu NL, Rath HC, et al. Use of self-expandable plastic stents for the treatment of esophageal perforations and symptomatic anastomotic leaks. Endoscopy 2004;36:695-699.

70. Sharaiha RZ, Kumta NA, DeFilippis EM, et al. A large multicenter experience with endoscopic suturing for management of gastrointestinal defects and stent anchorage in 122 patients: a retrospective review. J Clin Gastroenterol 2016;50:388-392. 